\title{
Comparison of topical breast milk versus dry cord care on umbilical cord separation, complications and cord colonization
}

\author{
Amir-Mohammad Armanian \\ Isfahan University of Medical Sciences \\ Behzad Barekatain \\ Isfahan University of Medical Sciences \\ Nima Salehimehr \\ Isfahan University of Medical Sciences \\ Atefeh Sharifian \\ Isfahan University of Medical Sciences \\ Zahra Shirani \\ Shaheed Beheshti University of Medical Sciences \\ Asma Javid ( $\square$ asma66javid@yahoo.com ) \\ Iran University of Medical Sciences https://orcid.org/0000-0001-8711-5270
}

\section{Research}

Keywords: Umbilical cord care, Very low birth weight, Human milk, Separation time, Cord colonization

Posted Date: May 5th, 2020

DOl: https://doi.org/10.21203/rs.3.rs-25714/v1

License: (c) (i) This work is licensed under a Creative Commons Attribution 4.0 International License. Read Full License 


\section{Abstract \\ Introduction:}

Neonatal death due to infections is still a great concern worldwide. Umbilical cord related infections play significant role in the neonatal mortality specially in very low birth weight infants, mother chorioamnionitis and premature rupture of membranes. It is associated with umbilical colonization, delayed separation and poor hygiene. In the current study, effect of topical breast milk usage with dry cord care on separation time, complications and colonization were compared.

\section{Methods}

This is a randomized clinical-trial on 150 very low birth weight neonates in 2016-18. Patients' were divided in two groups; Group-M ( $\mathrm{N}=73$ ) (3-4 drops of maternal breast milk were dropped on the umbilical cord stump within eight hours of birth and went on every eight hours until 48-hours after cord separation) and Group-D ( $\mathrm{N}=77$ ) (the umbilical cord was drought gradually in open air). Umbilical cord culturing was performed from cord stump within 2-4 hours after delivery, three days after birth and at the day of separation. Cords were assessed considering omphalitis, bad smell, exudates formation and granulation tissue.

\section{Results}

Neonates of two groups were not statistically different regarding separation time $(P=0.09)$, incidence of omphalitis $(P=0.16)$, bad odor $(P>0.99)$, exudative secretions $(P=0.97)$, granulation tissue $(P=0.96)$ and sepsis $(P=0.13)$. In addition, hospitalization duration $(P=0.71)$, time to reach full enteral feeding $(P=$ $0.31)$ and death $(P>0.99)$ were not statistically different. Three times cultures derived from two groups presented no significant difference $(P>0.05)$.

\section{Conclusion}

Based on findings of the current study, neither topical breast milk nor dry cord care was superior considering separation, associated complications and colonization. As neonatal death is still a serious concern worldwide and lacking of unanimous approach for prevention of cord related complications, further studies are strongly recommended.

\section{Introduction:}

Neonatal death has still remained an important issue in neonatal care systems, accounts for up to 1.6 million deaths annually in developing countries ${ }^{1}$. This health concern and neonatal sepsis is even more serious in developing countries ${ }^{2}$ as mortality in the first ten days of life is up to 42 percent ${ }^{3}$. A recently separated umbilical cord could be a route for bacteria entrance and develop serious infections.

Notably, annually one million deaths occur due to bacterial ascending infection of umbilical cord worldwide ${ }^{4}$. In fact, umbilical tissue is a reservoir for bacteria that potentially may enter the blood flow within first 2-3 days of the life when the umbilical vein is still patent ${ }^{4}$. This event may lead to neonatal sepsis or simply omphalitis ${ }^{4}$. The most common cultured colonies responsible for this colonization are group B streptococcus (GBS), Staphylococcus aureus and Escherichia coli (E. coli) ${ }^{5}$. This colonization may even occur with unusual colonies such as those derived from health-care systems environment or normal skin flora. Regardless of type of colonized bacteria, this colonization can lead to life-threatening sepsis ${ }^{6}$. Home delivery, non-sterile delivery or prolonged delivery, premature rupture of membrane, umbilical cord catheterization and low birth weight are among the most important risk factors of umbilical cord infection 7,8 .

Recently, increased attention in care giving to neonates have decreased rate of neonatal sepsis due to umbilical colonization in special. These strategies include reduction in number of caregivers to a neonate, utilizing disinfection solutions prior to and after being in touch with a neonate and hygiene and postnatal care protocols ${ }^{9,10}$.

Based on limited evidence in developing countries, the only recommendation of umbilical cord care was dry cord care ${ }^{11}$. Within recent years, various chemicals have been used in this regard including ethanol, triple dye, povidone iodine, silver sulfadiazine and chlorhexidine. The outcomes of each compound was controversial, sometimes their inability to cover all type of microorganisms and sometimes posing considerable adverse effects ${ }^{1,12}$.

Whereas harmful traditional routes of umbilical cord-care are still prevalent ${ }^{1}$, introduce safe and effective control ways seems necessary. Also using natural stuff for cord care is more acceptable for parents. Anti-inflammatory effect of human milk was supported by considerations such as weak activity of milk leukocytes and presence of anti-inflammatory components which can be restrict inflammatory progress.

Due to these observations in the current study, we have aimed to assess the effect of local mother's own milk on the time of umbilical cord separation and bacterial colonization among very low birth weight neonates and compare its results with routine dry cord care.

\section{Methods:}


This is a randomized clinical trial conducted on 150 very low birth weight neonates in Shahid Beheshti and Alzahra Hospitals (affiliated to Isfahan University of Medical Sciences) in 2016-18.

All of very low birth weight neonates $(\leq 1500 \mathrm{gr})$ were included. Those whose parents' presented their dissatisfaction of participating in the study and neonates who presented early onset sepsis, congenital anomalies, perinatal asphyxia, any requirement to umbilical catheterization or abdominal surgery, requirement to be fed with other compounds except breast milk and those neonates with over 1500-gram birth weight were excluded.

Study protocol was approved by Isfahan University of Medical Sciences Ethic Committee and conducted based on No. IRCT2017052110026N8 code. Study process and all required information were presented to neonates' parents and then they all signed their written consent of their child participation in the study.

Demographic information about neonates including age of birth, birth weight and gender were recorded in a checklist.

Participants who were chosen through simple sampling were randomly divided into two groups using random allocation software. In this regard, the software provided a number to each neonate. Even numbers were supposed as members of dried cord care (group D: control group) ( $\mathrm{N}=77)$ and odd numbers were members of local milk care (group M: case group) $(\mathrm{N}=73)$.

All patients' umbilical cords were cut in delivery room with sterile equipment. Then the umbilical cord was not disinfected with any types of disinfection materials and even was not cleaned with sterile gauze. Then they were transmitted to the neonatal intensive care unit (NICU). The entire included neonates were breastfed during the study. In group M, 3-4 drops of mother's own milk were dropped directly from mother's breast on the umbilical cord stump within eight hours of birth and this process went on every eight hours until 48 hours after umbilical cord separation. The dropped milk remained on the umbilical cord stump and was not washed at all. In addition, the umbilical cord was not covered under neonates' diaper. In group D, the umbilical cord was drought gradually in open air. No substance including mother's own milk or any other chemical was used in order of cord drying.

Umbilical cord culture for assessment of colonization was performed from cord stump in sterile conditions and transferred to the hospital laboratory quickly. This process was done three times; at first within 2-4 hours after delivery, then within three days after birth and the ratter was done at the day of cord separation.

Because of sever prematurity all of the participant went under antibiotics treatment and during the study members of both groups were observed considering signs/symptoms of infection including omphalitis, bad smell, exudates formation and granulation tissue.

Then data analysis was carried out using SPSS-20 (IBM® SPSS ${ }^{\circledR}$ Statistics; The United States). The data distribution was investigated using the KolmogorovSmirnov test. One-way ANOVA, the Kruskal-Wallish, and the Mann-Whitney U tests were used to compare the continuous variables. The Kaplan-Meier method with the log rank test was used to investigate the effect of interventions on primary and secondary clinical outcomes. Hazard ratio and $95 \%$ confidence intervals $(\mathrm{Cl})$ were calculated using the Cox regression and modifying the effect of gestational age and birth weight as the confounding factors. The result of quantitative variables with normal distribution and quantitative variables with abnormal distribution were reported as mean \pm standard deviation(SD) and range, respectively. All tests are of two-tailed structure and P-vales $<0.05$ was considered as significant level.

The sample size of this study calculated as 32 neonates in each group and for more assurance we studied 120 neonates.

$$
\mathrm{xn}=\frac{\left(\mathrm{Z}_{1}+\mathrm{Z}_{2}\right)^{2} * 2 \mathrm{~S}^{2}}{d^{2}}
$$

$$
\mathrm{xn}=\frac{\left(\mathrm{Z}_{1}+\mathrm{Z}_{2}\right)^{2} * 2 \mathrm{~S}^{2}}{d^{2}}
$$

\section{Results:}

Throughout the trial, a total number of 246 preterm infants were assessed for eligibility. Of these, 49 neonates were ineligible due to not meeting inclusion criteria and further 47 ones were excluded as their parents were reluctant for their children participation in the study, major congenital anomalies, perinatal asphyxia, need to umbilical cord catheterization and trend to scrubbing other agents instead of mother's own milk. Eventually, 150 very low birth weight (VLBW) neonates whose parents signed the consent form of study participation were studied. Among them number of 77 persons were members of group D and remained 73 ones were group $\mathrm{M}$ members (Figure-1).

The primary assessment of this study was comparison of umbilical cord separation between group $\mathrm{D}$ and group M. No significant difference was detected between two groups, as group $M$ mean separation time was 12 days $(5-28)$ while group $D$ was 13 days $(6-82)(P=0.09)$.

Table 1 presents adverse effects occurred during the study. Based on this table, there was no difference between two groups regarding occurrence of omphalitis, bad odour, exudative secretion, granulation tissue and sepsis $(P>0.05)$. The required time to start enteral feeding was not significantly different between group $D$ and group $M(P=0.31)$. Other variables including interventricular haemorrhage $(\mathrm{IVH})$ and patent ductus arteriosus $(\mathrm{PDA})$ showed no statistical difference between two groups $(P=0.25)$. Further findings are demonstrated in Table 1. 
Table 1

Outcomes and clinical characteristics of study infants (group M vs. group D)

\begin{tabular}{|c|c|c|c|c|}
\hline \multicolumn{2}{|l|}{ Variables } & M (Milk) group $(n=77)(\%)$ & D (Dry) group $(n=73)(\%)$ & P Value \\
\hline \multicolumn{2}{|c|}{ Gestational age (week) (mean \pm (SD)) } & $30.14 \pm 2.06$ & $29.95 \pm 2.01$ & 0.56 \\
\hline \multicolumn{2}{|l|}{ Birth weight $(\mathrm{g})($ mean $\pm \mathrm{SD})$} & $1224.16 \pm 207.99$ & $1172.80 \pm 209.09$ & 0.13 \\
\hline \multirow[t]{2}{*}{$\operatorname{Sex}(N)$} & Male & $42(53.8 \%) /$ & $38(51.4 \%)$ & \multirow[t]{2}{*}{0.95} \\
\hline & Female & $35(46.2 \%)$ & $35(48.6 \%)$ & \\
\hline \multicolumn{2}{|c|}{ Umbilical cord separation time (day) (median (range)) } & $12(5-28)$ & $13(6-28)$ & 0.09 \\
\hline \multirow[t]{4}{*}{ Umbilical cord complications } & Omphalitis & $3(3.8 \%)$ & $2(2.7 \%)$ & 0.16 \\
\hline & Bad Odour & $0(0 \%)$ & $0(0 \%)$ & $>0.999$ \\
\hline & Exudative secretion & $1(1.3 \%)$ & $1(1.3 \%)$ & 0.97 \\
\hline & Granulation tissue & $1(1.3 \%)$ & $0(0 \%)$ & 0.96 \\
\hline \multicolumn{2}{|l|}{ Sepsis } & $32(41.0 \%)$ & $40(53.4 \%)$ & 0.13 \\
\hline \multicolumn{2}{|l|}{ NEC } & $15(19.2 \%)$ & $16(21.3 \%)$ & 0.10 \\
\hline \multicolumn{2}{|c|}{ Time to reach full enteral feeding (day) (median (range)) } & $12(4-58)$ & $12(5-41)$ & 0.31 \\
\hline \multicolumn{2}{|l|}{ Interventricular haemorrhage } & $19(24.4 \%)$ & $16(21.3 \%)$ & 0.19 \\
\hline \multicolumn{2}{|l|}{ Patent Ductus Arteriosus } & $16(20.5 \%)$ & $13(17.3 \%)$ & 0.25 \\
\hline \multicolumn{2}{|c|}{ Duration of hospitalization (day) (mean \pm (SD)) } & $31.18 \pm 18.16$ & $30.18 \pm 14.85$ & 0.71 \\
\hline \multicolumn{2}{|l|}{ Death } & $0(0 \%)$ & $0(0 \%)$ & $>0.999$ \\
\hline
\end{tabular}

Table 2 shows the comparison of Bacterial and fungal colonization in three cultures taken in different times from each group. In the first culture derived from each group, $83.1 \%$ of negative culture was detected in group $M$ and $79.9 \%$ of group $D$ cultures were negative $(P=0.39)$. Further cultures of second and third times were not different between groups as well $(P=0.28$ and 0.85 respectively) (Table 2).

Table 2

Bacterial colonization in three times of umbilical cord swab cultures (Milk vs. Dry groups)

\begin{tabular}{|c|c|c|c|c|c|c|c|c|c|c|c|}
\hline $\begin{array}{l}\text { Swab } \\
\text { Cultures }\end{array}$ & groups & $\begin{array}{l}\text { No } \\
\text { growth }\end{array}$ & Enterobacter & E.coli & Pseudomonas & $\begin{array}{l}\text { Staphylococcus } \\
\text { aureus }\end{array}$ & Acinetobacter & Klebsiella & $\begin{array}{l}\text { gram- } \\
\text { positive } \\
\text { Bacilli }\end{array}$ & $\begin{array}{l}\text { gram- } \\
\text { negative } \\
\text { Bacilli }\end{array}$ & Fungus \\
\hline \multirow{4}{*}{$\begin{array}{l}\text { Swab } \\
\text { Culture } \\
1\end{array}$} & \multirow{2}{*}{$\begin{array}{l}\text { Milk } \\
\text { group }\end{array}$} & \multirow{2}{*}{$\begin{array}{l}64 \\
83.1 \%\end{array}$} & 0 & 0 & 1 & 7 & 2 & 1 & 0 & 0 & 1 \\
\hline & & & $0.0 \%$ & $0.0 \%$ & $1.3 \%$ & $9.1 \%$ & $2.6 \%$ & $1.3 \%$ & $0.0 \%$ & $0.0 \%$ & $1.3 \%$ \\
\hline & \multirow{2}{*}{$\begin{array}{l}\text { Dry } \\
\text { group }\end{array}$} & \multirow{2}{*}{$\begin{array}{l}59 \\
79.7 \%\end{array}$} & 1 & 2 & 0 & 6 & 1 & 0 & 2 & 2 & 1 \\
\hline & & & $1.4 \%$ & $2.7 \%$ & $0.0 \%$ & $8.1 \%$ & $1.4 \%$ & $0.0 \%$ & $2.7 \%$ & $2.7 \%$ & $1.4 \%$ \\
\hline Swab & \multirow{2}{*}{$\begin{array}{l}\text { Milk } \\
\text { group }\end{array}$} & 12 & 7 & 7 & 2 & 23 & 4 & 7 & 3 & 0 & 2 \\
\hline \multirow{3}{*}{$\begin{array}{l}\text { Culture } \\
2\end{array}$} & & $16.0 \%$ & $9.3 \%$ & $9.3 \%$ & $2.7 \%$ & $30.7 \%$ & $5.3 \%$ & $9.3 \%$ & $4.0 \%$ & $0.0 \%$ & $2.7 \%$ \\
\hline & \multirow{2}{*}{$\begin{array}{l}\text { Dry } \\
\text { group }\end{array}$} & 14 & 8 & 5 & 0 & 30 & 6 & 5 & 1 & 1 & 0 \\
\hline & & $19.2 \%$ & $11.0 \%$ & $6.8 \%$ & $0.0 \%$ & $41.1 \%$ & $8.2 \%$ & $6.8 \%$ & $1.4 \%$ & $1.4 \%$ & $0.0 \%$ \\
\hline Swab & \multirow{2}{*}{$\begin{array}{l}\text { Milk } \\
\text { group }\end{array}$} & 7 & 10 & 5 & 0 & 25 & 1 & 5 & 2 & 0 & 0 \\
\hline \multirow{3}{*}{$\begin{array}{l}\text { Culture } \\
3\end{array}$} & & $9.6 \%$ & $13.7 \%$ & $6.8 \%$ & $0.0 \%$ & $34.2 \%$ & $1.4 \%$ & $6.8 \%$ & $2.7 \%$ & $0.0 \%$ & $0.0 \%$ \\
\hline & \multirow{2}{*}{$\begin{array}{l}\text { Dry } \\
\text { group }\end{array}$} & 11 & 6 & 8 & 0 & 23 & 2 & 6 & 2 & 1 & 0 \\
\hline & & $15.5 \%$ & $8.5 \%$ & $11.3 \%$ & $0.0 \%$ & $32.4 \%$ & $2.8 \%$ & $8.5 \%$ & $2.8 \%$ & $1.4 \%$ & $0.0 \%$ \\
\hline
\end{tabular}

\section{Discussion:}

Umbilical cord infection is a serious concern of neonatologists in both developed and developing countries. Variety of strategies has been experimented to control umbilical cord associated adverse effects. Dry cord care is the most common one even has been recommended by WHO. Moreover, numerous chemicals have been utilized to prevent or control these adverse effects ${ }^{1,13}$. Whereas harmful traditional routes of umbilical cord-care are still prevalent ${ }^{1}$, introduce safe and effective control ways seems necessary.

In the current study, we have compared outcomes of mother's own milk use versus routine dry cord care on umbilical cord associated adverse effects. Breast milk as the best feeding resource of new-borns is consisted numerous immunologic and disinfecting factors protecting neonates from different infections ${ }^{14}$. 
Two groups of the study were not statistically different regarding body birth weight, age of delivery and gender distribution. Therefore, probable confounding variables that may influence outcomes of this study were eliminated.

We found that required time for cord separation, time to reach full enteral feeding and duration of hospitalization were not statistically different two groups.

Previous studies have conducted their studies using variety of chemicals for cord infection prevention. Studies in literature have presented 4 to 16 days as usual duration of cord separation ${ }^{15,16}$. Meanwhile, mean time for cord separation applying nothing was 9 days that was somewhat fewer than our study 17 . While most of them have presented superiority of routine dry cord care, some other studies found controversial outcomes as followed. Acharya et al. compared povidone versus dry care and presented that dry care was accompanied with shorter required time for separation ${ }^{18}$. The other study by Luke et al. compared outcomes of chlorhexidine, soap and water and routine dry cord care. Outcomes of this study presented superior results of both dry cord care and soap and water versus chlorhexidine ${ }^{12}$. The other study by Quattrin et al. compared $70 \%$ alcohol use with dry care and as previous studies found shorter time required for cord separation in dry cord care in comparison to local $70 \%$ alcohol for cord caring ${ }^{19}$. In 2015 , Abbaszadeh et al. in a similar study to ours, utilized mother's own milk for cord care and compared its outcomes with use of chlorhexidine. They found that required time for cord separation in group under mother's own milk treatment was significantly less than what was found in those treated with chlorhexidine ${ }^{20}$.

Umbilical cord associated adverse effects was assessed as well. Regarding adverse effects including omphalitis, bad odour, exudates secretion, granulation tissue, sepsis and death, no statistical differences were found between two groups under treatment with mother's own milk and dry cord care. Further studies in this regard have been published using various chemicals, as in a study of Mullany et al. use of chlorhexidine led to fewer incidence of umbilical cord adverse effects ${ }^{21}$. This finding was confirmed by Nankabirwa et al. in a study conducted in Sub-Saharan, Africa ${ }^{22}$. Another study by Yulanda et al. tried to compare outcomes of mother's own milk application with ethanol and dry cord care. In their similar to us study, they presented superiority of mother's own milk use considering fewer required time of cord separation and also less incidence of cord related infections ${ }^{23}$. Golshan et al. compared umbilical adverse effects following topical administration of ethanol, breast milk and dry cord care. Although they presented superiority of breast milk considering cord separation, cord associated complications occurrence were not statistically different in three groups ${ }^{24}$.

The last assessment of this study was about bacterial/fungal colonization of cords in two groups. Cultures were non-colonized in $83.1 \%$ of case and $79.7 \%$ of controls at study initiation. Two other cultures were obtained from study population that showed no difference between two groups. Staphylococcus aureus was the most common microorganism in both groups and in all derived cultures, followed by Enterobacter, E. coli and Klebsiella respectively.

Stewart et al. in a comprehensive study tried to assess cord colonization in general. Similarly, to our study they declared Staphylococcus aureus as the predominant organism derived from cultures. Further organisms with less prevalence included Group $A$ and $B$ Streptococci, gram negative germs including $E$. coli, Klebsiella and Pseudomonas species ${ }^{25}$. These organisms were presented by other authors as well ${ }^{7,26}$.

In a study by Lyngdoh et al. they presented that chlorhexidine could considerably reduce cord colonization followed by breast milk to some extends and dry cord care respectively. In this study total of 105 subjects randomized into 3 groups (chlorhexidine, breast milk and dry care) and topical application was done daily until the cord separated. Cord swab was done at the birth, day 3 and day 5 after birth. Obtained samples of their study were colonized with similar microorganisms found in our study ${ }^{27}$.

The other study by Mahrous et al. presented outcomes inconsistent with ours as they detected significantly less colonization found in those underwent breast milk cord care ${ }^{28}$. Fewer sample size and applying breast milk in the 2-4 first hours of birth, were the two major differences in this study.

\section{Conclusion:}

Based on findings of the current study, neither topical mother's own milk nor dry cord care was superior considering cord separation, cord associated adverse effects and cord colonization. This lacking of difference may be attributed to routine use of antibiotics in premature neonates. In addition, the premature newborns were prone to hospital flora microbes during their NICU hospitalization, thus it can be concluded that there was no considerable element for pathogens growth on cord.

Differences of these study outcomes with previous studies shows controversial findings presented by authors worldwide. As neonatal death is still a serious concern worldwide and lacking of unanimous approach for prevention of umbilical cord related complications, further studies are strongly recommended.

\section{Declarations}

*Ethics approval and consent to participate: The trial was approved by the Human Research Ethics Committee of Isfahan University of Medical Sciences (IUMS), Isfahan, Iran and a written informed consent was obtained from patients' parents prior to participation in the present trial.

*Consent for publication: The Publisher has the Author's permission to publish the relevant Data.

*Availability of data and material: In order to access the data supporting our findings contact to corresponding author.

*Competing interests: There is no conflict of interest.

*Funding: There is no funding support.

*Authors' contributions: All authors contributed equally. 
*Acknowledgements: We thank our colleagues from Paediatric group in Isfahan University of Medical Sciences.

*Authors' information: As mentioned in the first page.

\section{References}

1. Nangia S, Dhingra U, Dhingra P, Dutta A, Menon VP, Black RE, et al. Effect of $4 \%$ chlorhexidine on cord colonization among hospital and community births in India: a randomized controlled study. BMC Pediatr. 2016;16(1):121.

2. Ganatra HA, Zaidi AK, editors. Neonatal infections in the developing world. Seminars in perinatology; 2010: Elsevier.

3. Liu L, Johnson HL, Cousens S, Perin J, Scott S, Lawn JE, et al. Global, regional, and national causes of child mortality: an updated systematic analysis for 2010 with time trends since 2000. The Lancet. 2012;379(9832):2151-61.

4. Sangkomkamhang US, Lumbiganon P, Prasertcharoensuk W, Laopaiboon M. Antenatal lower genital tract infection screening and treatment programs for preventing preterm delivery. Cochrane database of systematic reviews. 2015(2).

5. Chan GJ, Lee AC, Baqui AH, Tan J, Black RE. Prevalence of early-onset neonatal infection among newborns of mothers with bacterial infection or colonization: a systematic review and meta-analysis. BMC Infect Dis. 2015;15(1):118.

6. Julian S, Burnham C-AD, Sellenriek P, Shannon WD, Hamvas A, Tarr PI, et al. Impact of neonatal intensive care bed configuration on rates of late-onset bacterial sepsis and methicillin-resistant Staphylococcus aureus colonization. infection control hospital epidemiology. 2015;36(10):1173-82.

7. Sawardekar KP. Changing spectrum of neonatal omphalitis. Pediatr Infect Dis J. 2004;23(1):22-6.

8. Forozeshfard M, Ghorbani R, Razavi M, Danaie N, Nooripour S. Comparison of the umbilical cord bacterial colonization in newborn infants rooming in with mothers and neonates admitted to neonatal intensive care unit. International Journal of Pediatrics. 2017;5(11):6009-15.

9. Imdad A, Mullany LC, Baqui AH, El Arifeen S, Tielsch JM, Khatry SK, et al. The effect of umbilical cord cleansing with chlorhexidine on omphalitis and neonatal mortality in community settings in developing countries: a meta-analysis. BMC Public Health. 2013;13(3):15.

10. Saleh J-EA, Nemecek J, Jones C. Impact of hygienic caring of the umbilical cord in the prevention of neonatal tetanus. 2015.

11. Zupan J, Garner P, Omari AA. Topical umbilical cord care at birth. Cochrane Database of Systematic Reviews. 2004(3).

12. Mullany LC, Darmstadt GL, Khatry SK, LeClerq SC, Katz J, Tielsch JM. Impact of umbilical cord cleansing with $4.0 \%$ chlorhexidine on time to cord separation among newborns in southern Nepal: a cluster-randomized, community-based trial. Pediatrics. 2006;118(5):1864-71.

13. Organization WH. Care of the umbilical cord: a review of the evidence. Care of the umbilical cord: a review of the evidence1998.

14. Mrisho M, Schellenberg JA, Mushi AK, Obrist B, Mshinda H, Tanner M, et al. Understanding home-based neonatal care practice in rural southern Tanzania. Trans R Soc Trop Med Hyg. 2008;102(7):669-78.

15. Karumbi J, Mulaku M, Aluvaala J, English M, Opiyo N. Topical umbilical cord care for prevention of infection and neonatal mortality. Pediatr Infect Dis J. 2013;32(1):78.

16. Soofi S, Cousens S, Imdad A, Bhutto N, Ali N, Bhutta ZA. Topical application of chlorhexidine to neonatal umbilical cords for prevention of omphalitis and neonatal mortality in a rural district of Pakistan: a community-based, cluster-randomised trial. The Lancet. 2012;379(9820):1029-36.

17. Pezzati M, Biagioli EC, Martelli E, Gambi B, Biagiotti R, Rubaltelli FF. Umbilical cord care: the effect of eight different cord-care regimens on cord separation time and other outcomes. Neonatology. 2002;81(1):38-44.

18. Acharya S, Sarafoglou K, LaQuaglia M, Lindsley S, Gerald W, Wollner N, et al. Thyroid neoplasms after therapeutic radiation for malignancies during childhood or adolescence. Cancer: Interdisciplinary International Journal of the American Cancer Society. 2003;97(10):2397-403.

19. Quattrin R, Kim lacobucci ALDT, Gallina L, Pittini C, Brusaferro S. 70\% Alcohol Versus Dry Cord Care in the Umbilical Cord Care: A Case-Control Study in Italy. Medicine. 2016;95(14).

20. Abbaszadeh F, Hajizadeh Z, Jahangiri M. Comparing the impact of topical application of human milk and chlorhexidine on cord separation time in newborns. Pakistan journal of medical sciences. 2016;32(1):239.

21. Mullany LC, Darmstadt GL, Khatry SK, Katz J, LeClerq SC, Shrestha S, et al. Topical applications of chlorhexidine to the umbilical cord for prevention of omphalitis and neonatal mortality in southern Nepal: a community-based, cluster-randomised trial. The Lancet. 2006;367(9514):910-8.

22. Nankabirwa V, Tylleskär T, Tumuhamye J, Tumwine JK, Ndeezi G, Martines JC, et al. Efficacy of umbilical cord cleansing with a single application of $4 \%$ chlorhexidine for the prevention of newborn infections in Uganda: study protocol for a randomized controlled trial. Trials. 2017;18(1):322.

23. EFFECTIVENESS OF APPLYING BREASTFEEDING/MILK ON UMBILICAL CORD TOHASTEN UMBILICAL CORDREMOVAL COMPARED TO ETHANOL AND DRY CARE OF NEWBORN

LITERATURE REVIEW

Nita Arisanti Y, Andikawati A, Achmad Si. EFFECTIVENESS OF APPLYING BREASTFEEDING/MILK ON UMBILICAL CORD TOHASTEN UMBILICAL CORDREMOVAL COMPARED TO ETHANOL AND DRY CARE OF NEWBORN: LITERATURE REVIEW. 2016.

24. Golshan M, Hossein N. Impact of ethanol, dry care and human milk on the time for umbilical cord separation. J Pak Med Assoc. 2013;63(9):1117-9.

25. Stewart D, Benitz W. Umbilical cord care in the newborn infant. Pediatrics. 2016:e20162149.

26. Mullany LC, Darmstadt GL, Katz J, Khatry SK, LeClerq SC, Adhikari RK, et al. Risk factors for umbilical cord infection among newborns of southern Nepal. Am J Epidemiol. 2006;165(2):203-11.

27. Lyngdoh D, Kaur S, Kumar P, Gautam V, Ghai S. Effect of topical application of human breast milk versus $4 \%$ chlorhexidine versus dry cord care on bacterial colonization and clinical outcomes of umbilical cord in preterm newborns. Journal of Clinical Neonatology. 2018;7(1):25. 
28. Mahrous ES, Darwish MM, Dabash SA, Ibrahim M, Abdelwahab SF. Topical application of human milk reduces umbilical cord separation time and bacterial colonization compared to ethanol in newborns. Translational Biomedicine. 2012;3(1).

\section{Figures}

246 premature infants were screened

47 were excluded

11 refused to participate

4 Major congenital anomalies

5 Asphyxia

5 need to umbilical cord catheterization

7 scrubbing instead of mother milk

15 attending was not compliant

with the study protocol

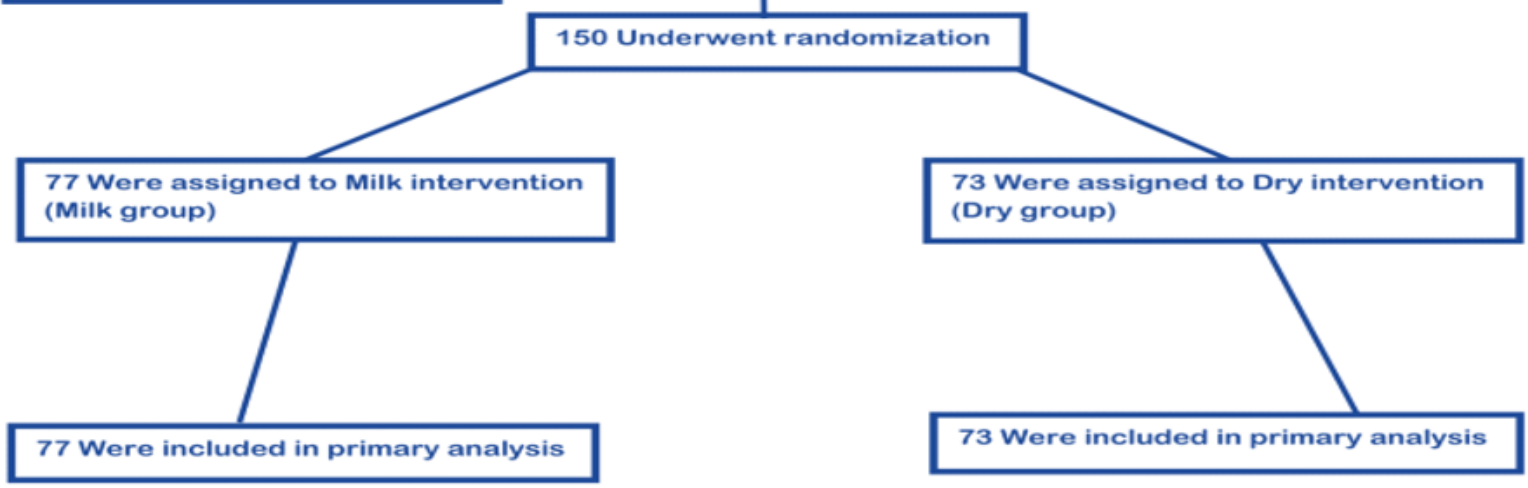

49 Were ineligible

5 VLBW but not premature

44 birth weight $>1500 \mathrm{gr}$.

\section{Figure 1}

CONSORT diagram showing the flowchart of subjects through each stage of study 